\title{
Towards Implementation of Blended Teaching Approaches for Higher Education in Myanmar
}

\author{
Phyo Thu Thu Khine $e^{\mathrm{a}}$, Htwe Pa Pa Win ${ }^{\mathrm{b}}$, Tun Min Naing ${ }^{\mathrm{c}}$ \\ ${ }^{a}$ University of Computer Studies, Hpa-an, 30101, Myanmar \\ ${ }^{\mathrm{b}}$ University of Computer Studies, Hpa-an, 30101, Myanmar \\ ${ }^{c}$ University of Computer Studies, Hpa-an, 30101, Myanmar \\ Email: phyothuthukhine@gmail.com
}

Received: 03 November 2020; Accepted: 23 November 2020; Published: 08 February 2021

\begin{abstract}
Blended teaching strategy becomes an integral part of the 21st-century education system to meet the industry 4.0 needs. As not only the online system can create the best system from the points of view of effectiveness and expending cost, but also the traditional teaching style cannot meet the higher level of industry needs. Therefore, the combination of the advancement of technology and the effective design of teaching theory appears in different blended systems to promote education level. This system also proposes a new model to initiate the teaching style that can supplement the requirements of this education era based on FLIP learning terms. The system is built by blending the online and face-to-face strategies using communication technology and multimedia components at pre-class, online test, and in-class times based on stakeholders' satisfaction with the system. The outcome intends to build an effective education system that facilitates the developing country, the Myanmar situation. Moreover, the research methodology goal includes improving the problem-solving ability and performance results of the university students and to increase the self-reflection of all participants.
\end{abstract}

Index Terms: Blending teaching, face-to-face, FLIP learning, industry 4.0, 21st century education, Myanmar, online, problem solving skill, self-reflection, teaching style

\section{Introduction}

As the fast development of the advancement of information technology in 21 st century, education system should be capable of blending with these innovations to improve the education level of the country. Especially, the Universities need to upgrade the teaching modes to be accompanied with the current situation Covid-19 epidemic and industry needs. The blended of the communication technology, the smart devices and multimedia devices, and the systematic teaching styles can create the good education system by integrating the face-to-face teaching and the online mode. The current online system has no good monitoring mechanism, reasonable feedback and the student feel. Therefore, the innovated blended teaching design should be ecological and organic combination, and based on the FLIP terms of flexible, learning culture, intentional and professional educator [1-3].

The human dimension is one of the pivotal factors in the success of blended learning. Although the blended systems have many advantages, these systems in most developing countries are not success because of the ignorance of human elements. If the human factors are effectively contributed, the successful lecturers and students may result and that can improve teaching and learning results [4]. Blended system with combination of self-reflection is more operative than traditional styles with regards to self-regulation and soft skill of the student and self-regulation processes for all participants are one of the crucial factors in the efficiency of blended learning [5,6].

Although most online education systems in the world around have many advantages and significant features, not all the systems are not suitable for developing country like our Myanmar. The developing country has limited technologies, strategies, and many difficulties in management for human beings and more challenges than the developed rich countries in many situations, especially in education. Therefore, the developing country needs to find suitable strategies for the education system with limited available resources to meet the modern industry needs.

Therefore, this paper is targeted to implement an effective ecological blended learning system for our developing country, Myanmar based on effective design without ignorance of the human factors. The remaining part of this paper is designed as follows. Section 2 introduces about the blended systems. Section 3 analyzed the previous works related to the blended systems. Section 4 described the proposed system design in detail. Section 5 concludes the proposed work at last. 


\section{Blended System}

The blended keyword for education means to fusion one with another, collaborative method, multimedia, multiresources, task-based and project-base. It is started from the Western education field of distance education and firstly introduced for enterprise training as blended learning theory which represents a combination of face-to-face lessons, different teaching media and digital learning strategic instructional integration. In other words, this blends the traditional education system with modern technologies $[7,8]$.

\subsection{Advantages of Blended Learning System}

- Place and time are free.

- The advantages from both modern learning and traditional learning are achieved.

- Active learning from passive learning is obtained.

- Enhance personalization, individualization and relevance self-reflection.

\subsection{Disadvantages of Blended Learning System}

- Online learning creates a new technology mode for both teachers and students.

- There exist hardware requirements such as multimedia devices, computer, smart phone and especially internet connection

- Too much time on screen times may harm to human health.

\subsection{Challenges in Blended Systems}

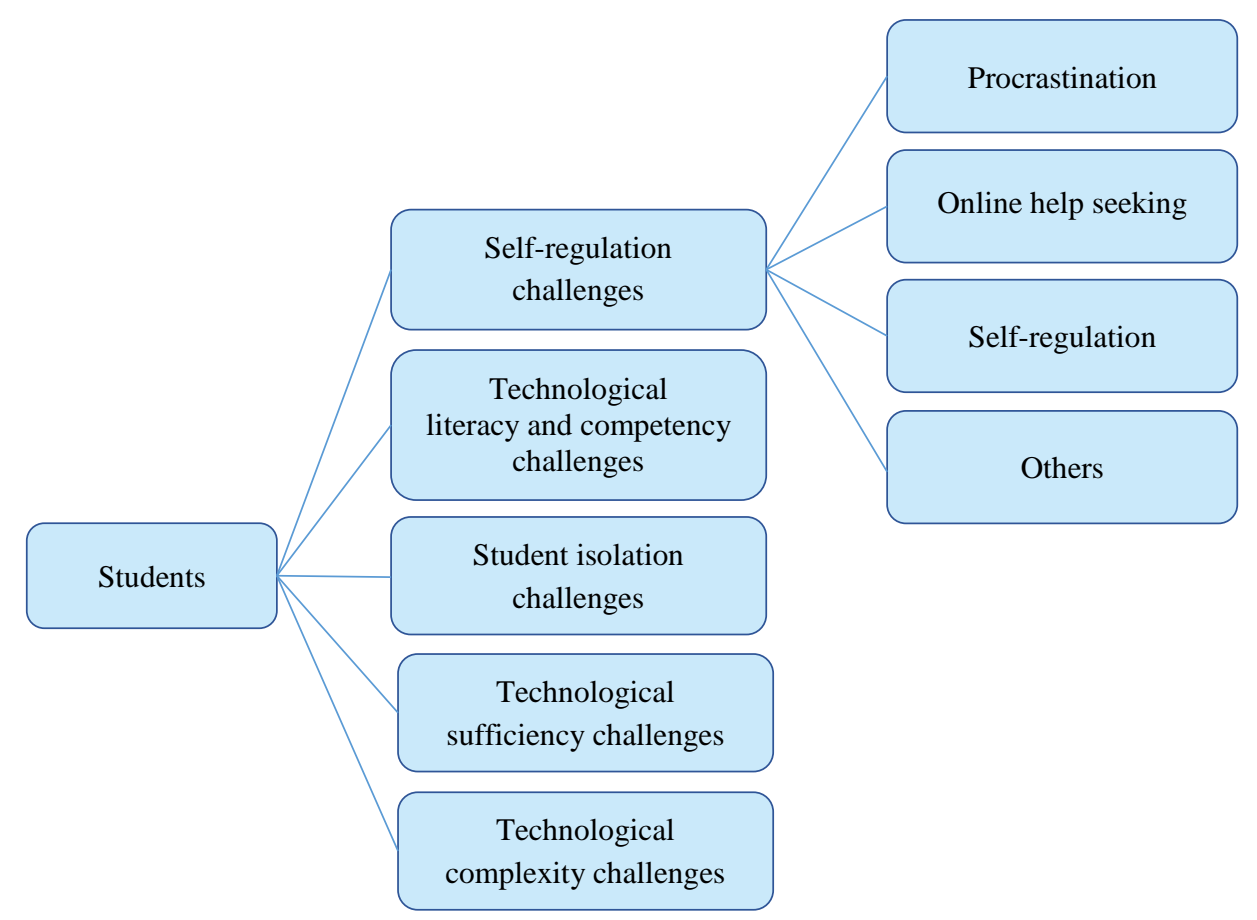

Fig. 1. Student challenges from blended system

The challenges that can arrive from blended systems can be classified into student challenges, teacher challenges, educational institution challenges as indicated in Figure 1 to 3 [9]. The students face many challenges as shown in Fig.1. The students in a developing country may face many technology challenges in literacy, sufficiency, and complexity as they have little chance to use new modern technology and need more time to be friendly used even available. When the student can use a modern device, they spend much time on those devices and may be isolated. Moreover, they may have self-regulation problems because most of the online courses can be flexible schedules and this situation may tend to be lazy or delayed person. They depend on online seeking for help and reduce their self-regulation ability. The challenges for the teachers are depicted in Fig. 2. The teachers may have difficulties in technologies for preparing the online video lectures in literacy, operation, their belief on teaching devices. The institution also has encounters with which system or devices are provided to the education process, how to train the teachers and students to use the modern teaching components and other management procedures as shown in Fig. 3. 


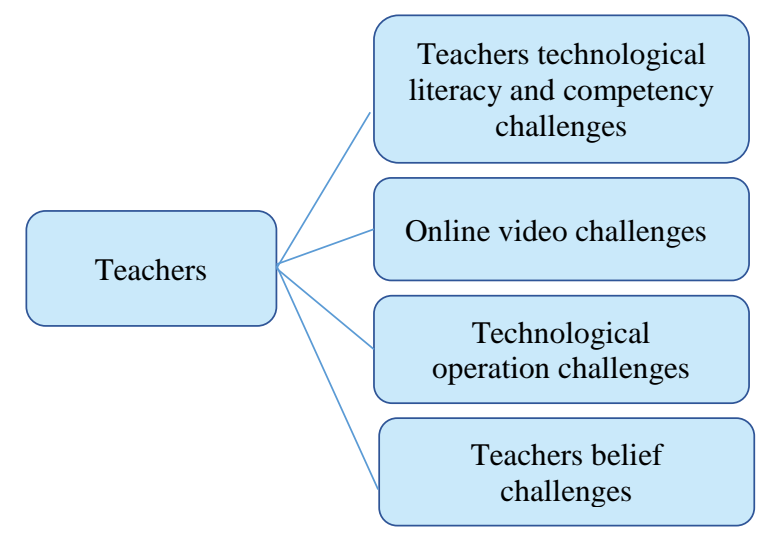

Fig. 2. Teacher challenges from blended system

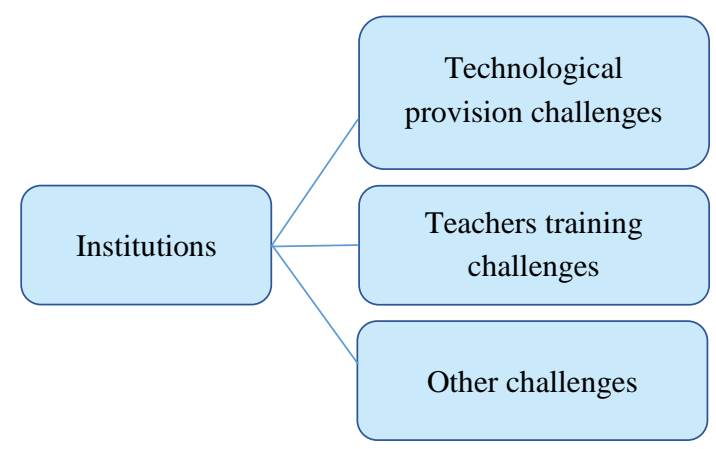

Fig. 3. Institutional challenges from blended system

\section{Literature Reviews}

The authors in [9] revealed the challenges of blended learning methodologies from teachers, students and institutions points of views as a valuable systematic review work between 2014 and 2018 papers. They showed distinctly the teachers' difficulties on the usage of teaching technologies and described clearly that self-regulation is the most important key challenge for students. They pointed out the troubles in finding the right enough learning infrastructures of the educational institutions. Their aim is to assist in finding the solutions for the encounter problems of blended learning with online methods in education.

In [4], the influence of human factors when implementing learning management system in developing countries are analyzed and designed a framework to tackle these difficulties. They stated that human dimension is more important than technological dimension to implement an effective LMS in universities and colleges. They designed their learning system focuses on improving the user's enjoyment and self-efficacy. They recommended that the universities need to encourage giving proper introducing training strategies as many as possible for all participants in education including students, teachers, staffs and managerial people. They also described not too much expectation for the participants for learning management system as they have negative influence of LMS, and the brand or software used for LMS should be the most familiar to the users.

The blended learning implementations for medical related education have been done in [10-15]. The blended learning technique for medical student in Motivational Interviewing (MI) is developed for Universities in Germany in [10] where the successful learning of students was measured with administered multiple-choice tests before and after the courses to evaluate subjective essential knowledge and skills. The execution of blended learning methodology for third-year pharmacy students' MI can be discovered in [11] where the ability of students' recognizing and formulation of responses after the training has been assessed by using e-learning quizzes, in-class practice sessions and final assessment videos. The improvement of blended learning framework for medical physicists of the Australian University can be observed in [12] where the design is to growth active learning by scaffolding the in-class activities with online tasks and reinforced by virtual actuality simulations. This design creates the team participation of the academic and the clinical medical physicists as education experts to expand student engagement for extremely specialized areas of study. The scoping review for the existing blended learning system for undergraduate nursing education has been made by the experts in [13]. Various blended learning methodologies for eight types of nursing themes that are based on the major happening things in the classroom is illustrated. The objective is to teach the nurses with an extensive variety of nursing skills and content by using blended learning in labs or clinical setting. The blended learning quantitative surveys for the nursing education has also done in [14] to develop Minimally Invasive Surgery (MIS). The satisfaction, perception and interest of the students are evaluated and the validation for the online blended theoretical module is performed. They 
suggested that simple ICT based tool should be used for blended learning on nursing education. The researchers in [15] proposed the blended learning mechanism for the German pharmacy students to improve the diabetes counseling skills and communication skills. The approach is blended the e-learning mechanisms and objective structured clinical examinations (OSCEs). The analytical checklists and global rating are applied to assess the skills and the students' satisfaction is measured by using surveys.

The scheme of blended learning in engineering rated education paradigms has been performed in [16-18]. The blended learning mechanism for project management (PM) course for architecture students has been proposed in [16]. The blended teaching methods are investigated whether it can support knowledge or not to architecture student with two case studies in PM course. The blended work for the digital measurement for engineering students has been done in [17]. The engineering students used a lot of geodetic equipment in vocational training of engineering geodesy course. The virtual learning tools and mobile devices are used as the virtual laboratory equipment to provide the students at an early stage of training. The blended learning of distance and mobile technology and business game theories are applied to implement as "flipped class". The learning method for Electrical Engineering students are blended with visual aids in [18]. They designed 3R model; Relate(what), Re-image(how) and Re-design(why) to incorporate the real-world visual life for third year electrical engineering undergraduate student. They evaluated their blended theories for technical challenges problem with customers and roof top solar system and they get the better improvement of confidence, understanding and engagement in student satisfaction than the normal learning.

Some of the blended learning paradigms for computer science are implemented in [19-23]. The combination of physical space and the achievement of Web Programming Grading Assistant (WPGA) strategies for all the programming languages are proposed in [19]. They design a blended system to track the student's performance not only digital space but also in physical space by using WPGA and face-to-face paradigms. They innovated educational technology from paper-based grading assessment items to provide feedback and graded results via online. They described that the more reviews or feedback can give to the students, the greater the learning efforts from the student can get. Then, the specific programming languages for C [20] and Python [21], and the other subjects Cyber Security [22] and Computer Organization [23] are implemented. In [20], the authors proposed to teach C++ subject in blended learning. They designed giving lecture and testing tutorials in face-to-face ideas, but the student can learn video with Moodle-platform and the student are provided online feedback tools for question and answers. They evaluated the positive impact on students understanding of programming language from their blended learning mechanism. The blended framework for python language is invented in [21] with the initiative to industrial 4.0. They emphasized on Python among the programming language, as it is more popular than JAVA and MATLAB in the current industries. They tested on 20 students group where $80 \%$ are non-familiar with python but an interactive format with demos can improve the pace to be faster. The consideration for tutorials to be more interesting through Kahoot online platform. They can improve the participation, problem-solving strategies and programming skills of the student. The Cybersecurity subject blended learning methodology for different level of student was developed in [22]. They emphasize on self-reported data of students and measured their satisfaction and preferences from that reports. They tested on 174 students and collected data from pass 115 students. They designed the cybersecurity course for 6 weeks with only 2 lectures and 4 tutorials and the tutorial are implemented with ViLLE (ville.utu.fi) online-learning platform with immediate feedback. They proved the acceptability of student for blended learning methodology for cybersecurity subject. In [23], the authors proposed the blended learning for Computer Organization subject base on self-learning ability of the student. They transformed the teaching practice to self-learning behavior to improve the learning interest and motivation of the student. They designed lectures with online to learn at any time, the face-to-face discussion are implemented in classrooms; the teacher asks the questions and answer the students immediately for the exercise and objective questions. They evaluated their plan on 24 students and achieved on 23 students.

The effects of blended learning on English subject are analyzed by the group [7, 24, 25]. The authors in [24] showed the effects of E-learning, IT mechanisms on English subjects for EFL learners. They blended computer aided translation tools (CAT) to the normal English teaching and tested for Level 6 students for total number of 20. They used SDL Trados Studio tools and English Language Teaching (ELT) for ENG 3670 of EFL subjects. They address on both development of translation technology and software programs to improve the learners' performance and suggest the Universities to use their technology to increase the quality of student to compete for labor markets. The researchers in [7] innovated the English teaching model with three stages pre-class, online-class and post-class for advanced English course. They intend to reduce the corporate learning costs by using blended strategies. They designed DingTalk to use on Chaoxing learning platform to implement blended learning and achieved the better result in learning than the normal traditional teaching method. The blended system of the English subject for the Technical University is implemented in [25]. They designed and tested for English language for Electronics and computer sciences subjects. They designed to use multimedia devices and effective distance teaching mechanism on Moodle platform for English foreign language. They prove their mechanism by comparing the traditional method enrollment and e-learning enrollment of the students.

The execution of blended learning methodology for Mathematics is discussed in [26-28]. The authors in [26] designed to teach the mathematic by combining online teaching methods using Moodle platform and quasi-experiments using pre- test-post-test design. They achieved the positive effect on learning outcomes of the students and the better attitude of the studying mathematics from the students. They analyzed their design benefits using Analysis of 
Covariance, ANCOVA and Multivariate Analysis of Covariance (MANCOVA) techniques. The authors of over 20 years teaching experiences in [27] proposed the blended learning methods for Mathematics. They described the producing of effective teaching video for the mathematics and the values of Khan Academy online learning websites. The teachers need to track the students' progress and prepare the next lecture plan to improve the student involvement and ability. They tested for Pre-calculus course on 112 students and proved that effectiveness of integration of Khan Academy mechanism to the traditional teaching on Mathematics. The researchers in [28] designed for first year Engineering student using 3p model; presage, process and product. They success in self-discipline and correct attitude in first year students. They recommended that time budgets should be used to develop the improved study habits and success for realistic expectations work at university-level studies.

The learning mechanisms of blended structure for Physics have been worked in [29-31]. The authors of [29] have done the investigation for the effect of physics blending learning for the college course. They analyzed the gap between the blended strategies and traditional methods and improved the lecture-based instructions and misconceptions of learners from the statics of the video management websites. They recommended that their studies may achieve the higher performance and more skills of the students. The actual blended learning technique for the physics subject is implemented in [30] for the colleges in Nigeria. They designed Researcher Made Electromagnetic Theory Achievement Test, RMETAT for multiple-choice question of the instrument data collection. They evolved their plan with 287 Physics students using ANCOVA and mean standard deviation statistical tools. They proved that flipped classroom is the better strategy than traditional face-face strategy and gender is not the significant influence factor for the retaining of Physics concepts. The medical Physics education is pioneering pointed in [31] where Moodle is used for E-learning platform. The authors highlight the important role of blended learning in this time of COVID-19 crisis. They suggested using educational TV and radio as the additional measure and the material books should be distributed electronically.

All of the previous systems described above point out the strategic, difficulties, pros and cons, and challenges for the different blended education systems for different environments. This system proposes an effective eco blended system based on the best of the knowledge of these systems.

\section{Proposed System Design}

All the design for the teaching system is intended to get the good outcomes. However, there may be different construction methods and based on various logic. This system is designed to build the effective blended system based on the following logic design in Fig. 4. The effective design of the system is the based foundation to get a good model. The best design can give the satisfaction for all users who are the stakeholders of the system including management level, operation level and tactical level of the educational organization and the students. When the based two stages come success, the outcome of the effectiveness may be stay at the top. In other word, effectiveness of blended teaching system can be obtained from the user satisfaction, which can only be supported from the effective design.

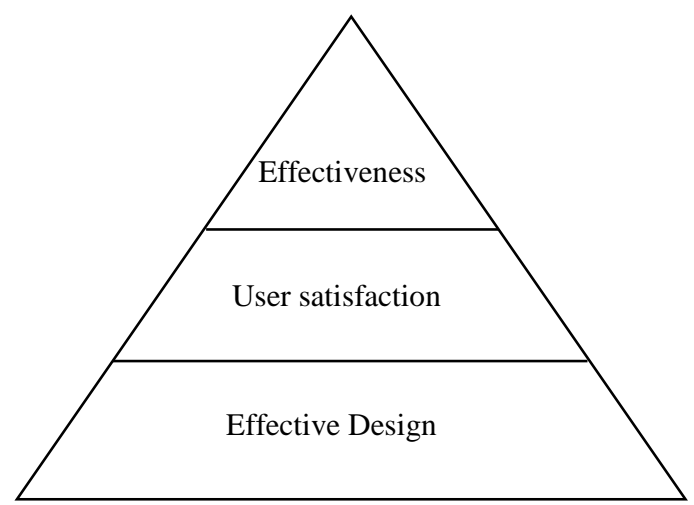

Fig. 4. The logic design for the proposed blended system

Then the blended teaching system is built based on the aforementioned logic. The steps of the proposed system design consist of the following procedures shown in Fig. 5. 


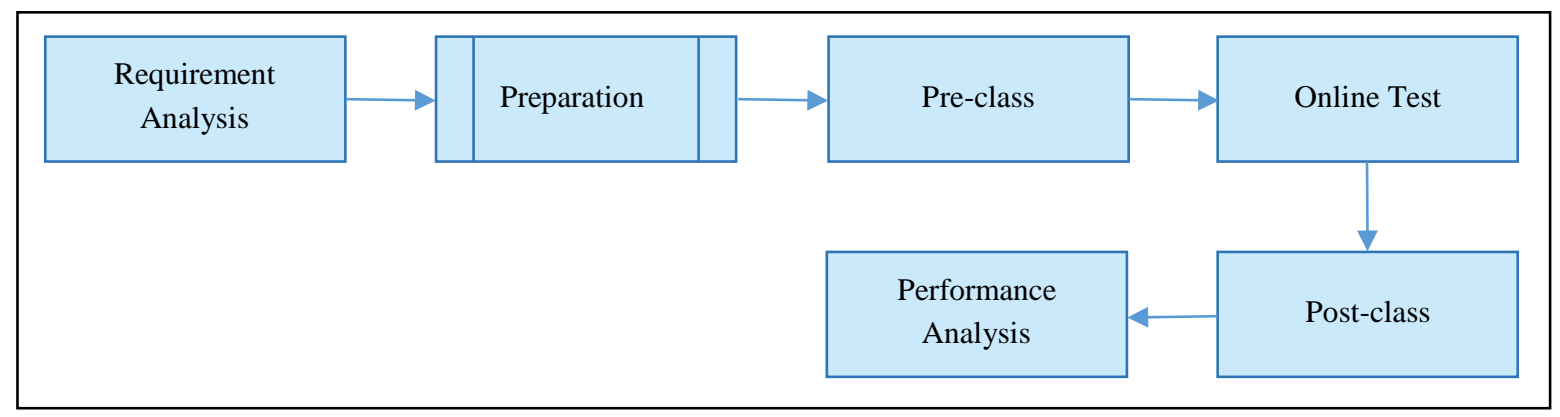

Fig. 5. The design of proposed blended system

\subsection{Requirement Analysis}

The analysis for the requirement of the system to be build is the first step for all the system. For this system, the requirement target should be the subjects to be build blended system. Therefore, the nature of the subjects needs to be analyzed as the design should not be the same for all the subjects. Some subject need to be practical practices and require determination how to grade student performance; automatically or manually. Then examination need to be done whether should be use LMS or not and if used, which type of LMS should be suitable depend on the subject's characteristic and which type can give the user self-reflection more. The systematic surveys should be taken from all the stakeholders of the system to improve the user satisfaction of the system.

\subsection{Preparation}

The preparation step can be started after the requirements are obtained. The preparation step includes listing books, giving the proper training for all stakeholders and making effective schedules, videos, assignments, quizzes and questions. The determination of which lecture books can be supplemented for the current industry needs is included in this step. The appropriate schedule for each subject that is suitable for all teachers and students is required to be exist. The preparation of videos needs to be more effective, i.e., the videos should include the embedded quizzes to avoid the students away from the lectures and should be short videos not more than 15 minutes. Moreover, the lecture video should not be dull PowerPoint for students and should create attractive moments using a Powtoon application with colorful graph and animation. The assignments need to be considered that the students themselves can do them and the quizzes and questions should be coverage the courses of the subject. Before the making lecture requirements, the stakeholders including students, teachers and staffs should be supported with multimedia devices such as smart TV and lab material and so on, and powerful paid version of tools and software and should be given the appropriate training of using modern technologies to produce the effective teaching materials.

\subsection{Pre-class}

This step involves providing and delivering the schedule, the books, lecture video and assignments to the students in time before the online test time. This step can be done in many ways using email or any online delivering system without using any LMSs and the student can learn at their personal time as they like.

\subsection{Online-Test}

This step involves the testing of the students' ability with the online technologies. This test may include quizzes, questions and some subjects need practical experiments or simulation. The testing time should be the same for all students for each subject and the test results and feedback should be given at the very same time to all students, especially after the exam time to prevent the answers sharing behavior. Therefore, this step can be implemented even using LMS or without using the LMSs system.

\subsection{In-Class}

The In-Class step is the discussion process or remedy process for the subjects. This is the face-to-face section of the teacher-student or student-student. The level of this step includes two parts in serial. The first one may be the remedy section and must participate for all students whose grading results are not good or fail, but the pass students can decide, as they desire. The second one must attend all students who pass or fail the online test as the teacher asks the question and the students give the answer immediately to grade their actual performance. This strategy can improve the students' ability, problem solving skill, and self-reflection. In addition, the teachers can analyze themselves what they need to do to improve teaching styles or be pleased themselves from the student performance or response. This grade should be a percentage of the entire grade of each student performance. Finally, the final grade of the student is produced by combining the online test result and the actual face-to-face results. 


\subsection{Performance Analysis}

This process is the measurement of effectiveness of blended teaching system. The effectiveness can be measured from the statistics of the students' grading results, involvements and the ability of problem-solving skill, and interviews or surveys should be taken for user satisfaction and feedback should be considered to produce the better courses.

\section{Conclusion}

The blended methodology for higher education system is proposed by combining the face-to-face mechanism and online teaching mechanism with the effective construction method. The design emphasizes on the user satisfaction and self-reflection of all stakeholders to produce the better student performance results. The proposed initiative development system may fulfill the requirements of education system in Myanmar. Since, the proposed system can be used with or without using LMSs system and if used can be designed to use little storage space; it can be mentioned as ecological teaching style. This teaching style may increase the students' ability and problem-solving skill that need for industry 4.0, and the teachers may be provided enough knowledge of modern IT devices and technologies and may have the much time to support students. The proposed system is supposed to implement the real education system from our university as the testing stage to the whole country as the resulting outcome would have many advantages and functionally effective. However, most educated researchers and academic counselors in our country are trying to find the best solution for our education system with various strategies.

\section{References}

[1] V. Pinos-Vélez, K. Quinde-Herrera, V. Abril-Ulloa, B. Moscoso, G. Carrión and J. Urgilés, "Designing the Pre-Class and Class to Implement the Flipped Learning Model in a Research Methodology Course," in IEEE Revista Iberoamericana de Tecnologias del Aprendizaje, vol. 15, no. 1, pp. 43-49, Feb. 2020, doi: 10.1109/RITA.2020.2978422.

[2] H. Chen, S. Wu and J. Shi, "Design of Online and Offline Blending Teaching Mode," 2020 IEEE 2nd International Conference on Computer Science and Educational Informatization (CSEI), Xinxiang, China, 2020, pp. 268-271, doi: 10.1109/CSEI50228.2020.9142519.

[3] Y. Zheng and Y. Chen, "Construction and Implementation of Blended Teaching Ecology Based on Cloud Class," 2020 IEEE 2nd International Conference on Computer Science and Educational Informatization (CSEI), Xinxiang, China, 2020, pp. 292295, doi: 10.1109/CSEI50228.2020.9142492.

[4] M. M. Alomari, H. El-Kanj, N. I. Alshdaifat and A. Topal, "A Framework for the Impact of Human Factors on the Effectiveness of Learning Management Systems," in IEEE Access, vol. 8, pp. 23542-23558, 2020, doi: 10.1109/ACCESS.2020.2970278.

[5] Aaron O. Thomas, Stacy A. Voils, Lindsey Childs-Kean, Modification of the self-regulated strategy inventory-self report for blended and team-based learning, Currents in Pharmacy Teaching and Learning, Volume 12, Issue 9, 2020, Pages 1093-1100, ISSN 1877-1297, https://doi.org/10.1016/j.cptl.2020.04.021.

[6] N. Lyz, A. Lyz, I. Neshchadim and V. Kompaniets, "Blended Learning and Self-Reflection as Tools for Developing ITStudents' Soft Skills," 2020 V International Conference on Information Technologies in Engineering Education ( Inforino ), Moscow, Russia, 2020, pp. 1-4, doi: 10.1109/Inforino48376.2020.9111723.

[7] D. Yuan-Bing and W. Jing-Zheng, "A Study on Providing Blended Learning Support to EFL Students of Advanced English Course," 2020 IEEE 2nd International Conference on Computer Science and Educational Informatization (CSEI), Xinxiang, China, 2020, pp. 230-234, doi: 10.1109/CSEI50228.2020.9142510.

[8] M. Kaur, "Blended learning - its challenges and future" 3rd World Conference on Learning, Teaching and Educational Leadership (WCLTA-2012), Procedia - Social and Behavioral Sciences, ISSN: 1877-0428, Vol: 93, Page: 612-617, 2013. https://doi.org/10.1016/j.sbspro.2013.09.248

[9] Rasheed Abubakar Rasheed, Amirrudin Kamsin, Nor Aniza Abdullah, Challenges in the online component of blended learning: A systematic review, Computers \& Education, Volume 144, 2020, 103701, ISSN 0360-1315, https://doi.org/10.1016/j.compedu.2019.103701.

[10] Keifenheim KE, Velten-Schurian K, Fahse B, et al. "A change would do you good": training medical students in Motivational Interviewing using a blended-learning approach-a pilot evaluation. Patient Educ Couns. 2019;102:663-669

[11] Michael A. Biddle, Rebecca M. Hoover, Teaching motivational interviewing in a blended learning environment, Currents in Pharmacy Teaching and Learning, Volume 12, Issue 6, 2020, Pages 728-734, ISSN 1877-1297, https://doi.org/10.1016/j.cptl.2020.01.027.

[12] Iwona Czaplinski, Andrew L. Fielding, Developing a contextualised blended learning framework to enhance medical physics student learning and engagement, Physica Medica, Volume 72, 2020, Pages 22-29, ISSN 1120-1797, https://doi.org/10.1016/j.ejmp.2020.03.010.

[13] Don M. Leidl, Lauren Ritchie, Neda Moslemi, Blended learning in undergraduate nursing education - A scoping review, Nurse Education Today, Volume 86, 2020, 104318, ISSN 0260-6917, https://doi.org/10.1016/j.nedt.2019.104318.

[14] Juan-Francisco Ortega-Morán, Blas Pagador, Juan Maestre-Antequera, Antonio Arco, Francisco Monteiro, Francisco M. Sánchez-Margallo, Validation of the online theoretical module of a minimally invasive surgery blended learning course for nurses: A quantitative research study, Nurse Education Today, Volume 89, 2020, 104406, ISSN 0260-6917, https://doi.org/10.1016/j.nedt.2020.104406. 
[15] Imaneh Farahani, Stephanie Laeer, Samieh Farahani, Holger Schwender, Anna Laven, Blended learning: Improving the diabetes mellitus counseling skills of German pharmacy students, Currents in Pharmacy Teaching and Learning, Volume 12, Issue 8, 2020, Pages 963-974, ISSN 1877-1297, https://doi.org/10.1016/j.cptl.2020.04.016.

[16] Laila M. Khodeir, Blended learning methods as an approach to teaching project management to architecture students, Alexandria Engineering Journal, Volume 57, Issue 4, 2018, Pages 3899-3905, ISSN 1110-0168, https://doi.org/10.1016/j.aej.2018.10.004.

[17] O. Solnyshkova and E. Dudysheva, "Mobile Technologies in Blended Learning of Engineering Students in Digital Measurements on Geodetic Equipment," 2020 V International Conference on Information Technologies in Engineering Education ( Inforino ), Moscow, Russia, 2020, pp. 1-5, doi: 10.1109/Inforino48376.2020.9111810.

[18] A. L. Liu, G. Nourbakhsh, N. Ghasemi, G. Ledwich, W. Miller and B. Zhu, "Do Real Life Visuals Help Students to Learn Engineering," 2019 4th International Conference on Intelligent Green Building and Smart Grid (IGBSG), Hubei, Yi-chang, China, 2019, pp. 291-295, doi: 10.1109/IGBSG.2019.8886213.

[19] I. Hsiao, P. Huang and H. Murphy, "Integrating Programming Learning Analytics Across Physical and Digital Space," in IEEE Transactions on Emerging Topics in Computing, vol. 8, no. 1, pp. 206-217, 1 Jan.-March 2020, doi: 10.1109/TETC.2017.2701201.

[20] K. Zeuch, S. Kaven and V. Skwarek, "Evaluation of a re-designed introductory course "Programming in C" with video support," 2019 18th International Conference on Information Technology Based Higher Education and Training (ITHET), Magdeburg, Germany, 2019, pp. 1-6, doi: 10.1109/ITHET46829.2019.8937347.

[21] M. Wende, T. Giese, S. Bulut and R. Anderl, "Framework of an Active Learning Python Curriculum for First Year Mechanical Engineering Students," 2020 IEEE Global Engineering Education Conference (EDUCON), Porto, Portugal, 2020, pp. 11931200, doi: 10.1109/EDUCON45650.2020.9125259.

[22] A. Farooq, A. Hakkala, S. Virtanen and J. Isoaho, "Cybersecurity Education and Skills: Exploring Students' Perceptions, Preferences and Performance in a Blended Learning Initiative," 2020 IEEE Global Engineering Education Conference (EDUCON), Porto, Portugal, 2020, pp. 1361-1369, doi: 10.1109/EDUCON45650.2020.9125213.

[23] Y. Hou, W. Wang, F. Liu, Z. Shan, J. Wang and L. Wang, "Exploration and Research of Blended Learning in the" Principles of Computer Organization"," 2020 IEEE 2nd International Conference on Computer Science and Educational Informatization (CSEI), Xinxiang, China, 2020, pp. 331-334, doi: 10.1109/CSEI50228.2020.9142513.

[24] Y. A. Gomaa, R. AbuRaya and A. Omar, "The Effects of Information Technology and E-Learning Systems on Translation Pedagogy and Productivity of EFL Learners," 2019 International Conference on Innovation and Intelligence for Informatics, Computing, and Technologies (3ICT), Sakhier, Bahrain, 2019, pp. 1-6, doi: 10.1109/3ICT.2019.8910326.

[25] N. A. Kopylova, "The Use of Modern E-learning Technologies at English Lessons in a Technical University Pedagogical Process," 2020 9th Mediterranean Conference on Embedded Computing (MECO), Budva, Montenegro, 2020, pp. 1-6, doi: 10.1109/MECO49872.2020.9134257.

[26] Lin, Ya-Wen et al. "The Effect of Blended Learning in Mathematics Course". Eurasia Journal of Mathematics, Science and Technology Education, vol. 13, no. 3, 2017, pp.741-770. https://doi.org/10.12973/eurasia.2017.00641a

[27] G. Krishnan and W. Dastakeer, "Mobile Classroom-Blended Learning Through Use of Technology," 2019 Advances in Science and Engineering Technology International Conferences (ASET), Dubai, United Arab Emirates, 2019, pp. 1-6, doi: 10.1109/ICASET.2019.8714286.

[28] Quinn, D., Aarão, J. Blended learning in first year engineering mathematics. ZDM Mathematics Education 52, $927-941$ (2020). https://doi.org/10.1007/s11858-020-01160-y

[29] Bazelais, P., Doleck, T. Investigating the impact of blended learning on academic performance in a first semester college physics course. J. Comput. Educ. 5, 67-94 (2018). https://doi.org/10.1007/s40692-018-0099-8

[30] Onyenma Chinwendu, Olele, Clara Nnoduka, Effect of Blended Learning on Students' Retention of Physics in Federal Colleges of Education in South East, Nigeria, International Journal of Education, Learning and Development, Vol.8, No.1, pp.66-76, January 2020

[31] Tabakova, V. E-learning - from first experiences in medical physics and engineering to its role in times of crisis. Health Technol. (2020). https://doi.org/10.1007/s12553-020-00474-x

\section{Authors' Profiles}

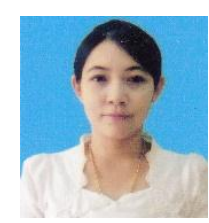

Phyo Thu Thu Khine received her Ph.D (IT) from University of Computer Studies, Yangon, Myanmar in 2012. She is currently working as a Lecturer at the University of Computer Studies, Hpa-an, Myanmar. Her research interests include Image Processing, Speech processing, Digital Signal processing, Database Management System, Big Data, Information Technology and Education.

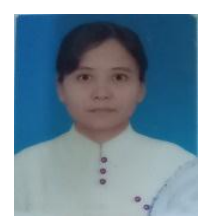

Htwe Pa Pa Win received her Ph.D (IT) from University of Computer Studies, Yangon, Myanmar in 2012. She is currently working as a Lecturer at the University of Computer Studies, Hpa-an, Myanmar. Her research interests include Image Processing, Speech processing, Digital Signal processing, Information Technology and Education. 
Tun Min Naing received his Ph.D (IT) from Russia. He is the second vice-president of the University of Computer Studies, Hpa-an. His research interests include Information Technology and Education.

How to cite this paper: Phyo Thu Thu Khine, Htwe Pa Pa Win, Tun Min Naing, "Towards Implementation of Blended Teaching Approaches for Higher Education in Myanmar", International Journal of Education and Management Engineering (IJEME), Vol.11, No.1, pp. 19-27, 2021. DOI: 10.5815/ijeme.2021.01.03 